\title{
Cidade, cultura e turismo: para além do entretenimento
}

\author{
City, culture and tourism: beyond entertainment
}

Inês Ulhôa ${ }^{1}$

Karina Dias ${ }^{2}$

\section{Resumo}

Este artigo tem por objetivo traçar algumas considerações acerca da relação possível entre cidade, cultura, memória e turismo na produção dos espaços voltados a atividades turísticas. Trazemos o debate com o propósito de discutir se a paisagem urbana apropriada e ressignificada pelo turismo está implicada nas tramas da ordem global capitalista.

Palavras-chave: Cidade. Turismo. Cultura. Memória. Entretenimento.

\section{Abstract}

This article aims to bring some considerations about the possible relationship between city, culture, memory and tourism in the production of spaces geared to tourism activities. Our purpose is to discuss if the urban landscape appropriate and re-signified by tourism is implicated in the plots of the global capitalist order.

Key words: City. Tourism. Culture. Memory. Entertainment.

A cada instante, há mais do que o olho pode ver, mais do que o ouvido pode perceber, um cenário ou uma paisagem esperando para serem explorados.

Kevin Lynch, A imagem da cidade

\section{Introdução}

O turismo, uma singularidade dentre tantas atividades exercidas pelos homens, serve para que as pessoas possam conhecer lugares, culturas, além de contribuir para a compreensão do lugar que ocupamos e da percepção de nós mesmos, como sujeitos ativos, capazes de interagir no mundo. E se pensarmos o turismo como um fenômeno pluridimensional, que envolve outros fenômenos sociais,

\footnotetext{
1 Jornalista e mestranda no Centro de Excelência em Turismo da Universidade de Brasília. E-mail: inesulhoa@gmail.com.

2 Professora doutora no Centro de Excelência em Turismo da Universidade de Brasília. E-mail: karinadias.net@gmail.com.
} 
culturais, políticos e econômicos, principalmente na sociedade contemporânea, guiada pelos progressos técnico-científicos e com o advento da internet, com seu enorme fascínio sobre as culturas humanas, em que as distâncias são encurtadas, unindo lugares e pessoas, disponibilizando o conhecimento e proporcionando nos comunicarmos abertamente para o mundo, temos uma prática complexa, que exige uma compreensão da produção dos espaços pelo homem.

Nessa contextualidade, pode-se verificar o caráter contingente da acumulação do capital na criação de grandes cidades e sua rápida urbanização e a consequente concentração no espaço de forças produtivas e do poder político e econômico. Ademais, a reflexão e o debate sobre as cidades revelam simultaneamente a crescente necessidade de rever conceitos, tal como a globalização ${ }^{3}$ (e seu uso político) e a emergência de valorização do lugar ou dos lugares como reveladores das realidades sociais.

Se a cidade é obra dos homens, seu cenário está sempre se modificando, conjugado às forças sociais que se interagem pelas relações cotidianas. Kevin Lynch (2010, p.1), ao traçar a fisionomia das cidades, do fato dessa fisionomia ter ou não importância e da importância de modificá-la, analisa como a paisagem urbana também é algo a ser visto e lembrado. "Cada cidadão", diz ele, "tem vastas associações com alguma parte de sua cidade, e a imagem de cada um está impregnada de lembranças e significados".

A imagem da cidade é alinhavada em meio à inventividade dos que a habitam. Mas como o mundo dos homens, de acordo com o pensamento marxista, é resultado da atividade dos próprios homens, a subjetividade e a objetividade se determinam mutuamente e sintetizam o ser social, que possui a crença na transformação e superação da contradição antagônica opressor/oprimido... Nessa paisagem urbana não somos meros observadores, somos parte. Por isso, devemos compreendê-la. E se a mudança "faz parte necessária da experiência cultural fora da qual não somos", como diz Paulo Freire (2000, p.31), "o que se impõe a nós é tentar entendê-la na ou nas suas razões de ser". Isso significa a importância de

\footnotetext{
${ }^{3}$ Stuart Hall, em seu livro A identidade cultural na pós-modernidade (2006, p. 67) pergunta "o que pode estar tão poderosamente deslocando as identidades culturais nacionais [...]?" Para ele, é a globalização, e recorre à concepção que Anthony Macgrew (1992) dá ao termo: "a globalização se refere àqueles processos atuantes numa escala global, que atravessam fronteiras nacionais, integrando e conectando comunidades e organizações em novas combinações de espaço-tempo, tornando o mundo, em realidade e em experiência, mais interconectado".
}

Cad. de Pesq. Interdisc. em Ci-s. Hum-s., Florianópolis, v.12, n.101, p.xxxxx ago/dez 2011 
percebermos a cidade como símbolo, onde inscrevemos nossas lembranças e nossas emoções.

\section{A força do mercado}

Decerto as cidades ocupam papel central na produção dos espaços, com todas as suas representações culturais, difundindo ideias, comportamentos, valores, formas de lazer etc. Mas também inventar sempre uma nova necessidade humana é a chave para a expansão do capitalismo sobre a vida urbana e a cultura que ela engendra. Por isso, pode-se considerar os espaços da cidade como um campo onde forças antagônicas se encontram: é onde a geopolítica do capitalismo impõe a sua força, incorporando e criando valor a espaços que passam por transformações profundas, mediados por interesses de grupos, dando a sua lógica a territórios turísticos e constituindo, assim, ícones culturais, como tantos espalhados pelas cidades do mundo. Ao valorizar os espaços urbanos como destinação turística, os agentes capitalistas intensificam a atividade social dos mercados e das pessoas com vistas ao processo de acumulação. Conforme observa o geógrafo David Harvey (2006, p. 148):

\footnotetext{
O desenvolvimento capitalista deve buscar uma solução de continuidade entre a preservação dos valores dos compromissos passados (assumidos em um espaço e tempo específicos) ou a sua desvalorização, para abrir espaço novo para a acumulação. Continuamente, portanto, o capitalismo se esforça para criar uma paisagem social e física da sua própria imagem, e requisito para suas próprias necessidades em um instante específico do tempo, apenas para solapar, despedaçar e inclusive destruir essa paisagem num instante posterior do tempo. As contradições internas do capitalismo se expressam mediante a formação e a reformação incessantes das paisagens geográficas. Essa é a música pela qual a geografia histórica do capitalismo deve dançar sem cessar.
}

Daí que emerge a urgência de ver a cidade, sistema dinâmico e complexo, não apenas como uso de um mercado global, em que a técnica da informação "tem um papel determinante sobre o uso do tempo, permitindo, em todos os lugares, a convergência dos momentos, assegurando a simultaneidade das ações" (SANTOS, 2011 , p. 25), mas também entrever nela o poder da cultura como aglutinadora de pessoas e propulsora do desenvolvimento material e humano da sociedade. 
Evidentemente, a percepção dos sujeitos sociais não está imune ao entendimento de que o Estado e o mercado são os atores hegemônicos no processo de produção de uma lógica que pode, também, ser destrutiva para o próprio desenvolvimento do turismo. Nessa perspectiva, é que concordamos com Marutschka Moesch, quando ela afirma que o desenvolvimento do conhecimento do turismo ocorre condicionado ao funcionamento da sociedade contemporânea, cuja importância "está atrelada à magnitude das cifras econômicas que cruzam as fronteiras internacionais" por meio da atividade turística. A partir da leitura que Moesch faz do contexto social onde o saber turístico se desenvolve, fica claro o uso do paradigma marxista para explicar que

a sociedade divide-se em duas partes, dialeticamente relacionadas, na qual sua força motriz é a luta de classes. Dentro desse paradigma, o Turismo é um campo produtivo, localizado na infraestrutura da sociedade, portanto determinado pelas forças de mercado - leia-se luta entre as diferentes classes sociais - reduzido a produto de consumo, acessível às classes economicamente dominantes (MOESCH, 2008, p.11).

É na perspectiva dessa dinâmica nas cidades que é possível entender que o ócio e o lazer são produtores também da dinâmica espacial. Milton Santos defendeu a ideia do espaço como resultado de uma relação indissociável entre sistemas e objetos, "casando duas coisas, ação e materialidade". Para ele, o que realmente entra na dialética social "não é o espaço tal como definido antes, como materialidade, mas o espaço vivido, usado pelos homens" (2004a, p. 25).

Essa questão se referencia no ponto de vista de quem vive na cidade, onde a pluralidade se impõe nos fazeres daqueles que a habitam. Portanto, participar de eventos na cidade revela que as escolhas individuais são resultado da sociabilidade dos sujeitos e traduzem o pertencimento a uma dada estrutura social, o que revela também o papel do espaço, onde a compreensão da ação humana tem de ser vista na realidade social. Nessas circunstâncias ocorrem as possibilidades de transformação do real, com a riqueza do agir, pois é por meio de intervenções, mesmo que singulares, que se processam as mudanças capazes de revelar sujeitos históricos. Nesse sentido, Paolo Rossi argumenta:

O mundo em que vivemos há muito tempo está cheio de lugares nos quais estão presentes imagens que têm a função de trazer alguma coisa à memória. Algumas dessas imagens [...] nos remetem ao passado de nossas histórias, à sua continuidade presumível ou real com o presente. 
Nos lugares da vida cotidiana, inúmeras imagens nos convidam a comportamentos, nos sugerem coisas, nos exortam aos deveres, nos convidam a fazer, nos impõem proibições, nos solicitam de diversas maneiras (2007, p.23).

Assim é que nos permitimos procurar compreender que a razão principal para esse conjunto de significados partilhados e construídos pelos homens para explicar o mundo está, justamente, nessa entrada em cena de novas formas integradoras da vida social e cultural. Indivíduos pautam suas existências procurando dar sentido à sua práxis não no sentido do ser individual, mas na dimensão do ser social, tal como Marx um dia apregoou ${ }^{4}$.

\section{0 uso dos lugares}

É emblemático que o espaço produzido historicamente possa condicionar a apropriação e o uso dos lugares e, assim, proporcionar também novas necessidades e novos desejos, pois a sociedade se realiza no espaço e a partir dela é que se pode compreendê-lo, conforme ensina Milton Santos (2009). Para ele, o espaço nada mais é do que a soma dos resultados da intervenção humana sobre a terra, "processo evidente nas cidades transformadas pela nova lógica do trabalho humano que (re)produz o tempo livre e o lazer na tendência da atividade turística" (COSTA, 2010, p. 27), que dá um sentido global sobre o local e dinamiza e transforma o espaço geográfico. Por isso, não se pode deixar de dar importância ao fenômeno turismo nesse processo complexo e dialético de produção do espaço, onde as contradições afloram, e o qual nos faz entender a realidade social.

Para além da materialidade dos espaços na cidade, é preciso ver as dimensões simbólicas que ela pode apresentar. Como palco, como lugar, a cidade abriga a história e os sujeitos que, com liberdade de escolhas, podem se excluir e se somar, num jogo dialético sem fim. Ao examinarmos o papel da cultura exercida na cidade, é possível constatar que uma cidade com vida cultural vibrante e criativa e capaz de aceitar as múltiplas diversidades culturais atrai para si tanto trabalhadores do conhecimento como visitantes que se interessam por atividades culturais. A

\footnotetext{
${ }^{4}$ Conforme Marx: "Idéias nunca podem executar absolutamente nada. Para a execução das idéias são necessários homens que ponham em ação uma força prática" (MARX; ENGELS, 2003, p.137).

Cad. de Pesq. Interdisc. em Ci-s. Hum-s., Florianópolis, v.12, n.101, p.xxxxx ago/dez 2011
} 
cidade que oferece seus espaços para atividades culturais torna-se um atrativo para as pessoas.

Para a leitura interpretativa dos lugares da cidade como possibilidades do turismo cultural, concordamos com Gastal e Moesch, para quem as pessoas moradoras ou usuárias das cidades fazem parte dos fluxos que percorrem os espaços citadinos e incentivá-las a viver a sua cidade e desfrutá-la, para além de suas rotinas, deveria ser uma prática constante, transformando, assim, essas pessoas em turistas em sua própria cidade. Para essas autoras (2007, p.19),

olhar a cidade com maior cuidado não é mais uma tarefa exclusiva dos turistas que a percorrem. Mesmo para os moradores das cidades, a sua complexidade coloca, cada vez mais, maiores desafios. Decifrá-los é fundamental para sobreviver e viver nas cidades com qualidade.

Nessa movimentação, há, evidentemente, o contato humano e cultural, pois a cidade "é o lugar onde há mais mobilidade e mais encontros" (SANTOS, 2004b, p. 319). Mas se levarmos em conta que hoje, com as novas tecnologias, quase tudo se pode fazer sem que saiamos de nosso ambiente, até mesmo viajar virtualmente, ir ao shopping virtualmente, fazer amizades virtualmente ${ }^{5}$, podemos, então, discutir se o turismo cultural pode, sim, ser realizado, por moradores das cidades. Um passeio pela feira do Guará, bairro do Distrito Federal, por exemplo, pode ser culturalmente mais expressivo para um morador da cidade do que uma viagem a Miami, ou, simplesmente, comer um pastel com caldo de cana na Rodoviária do Plano Piloto, com vistas para a Esplanada dos Ministérios, de onde se descortinam a Catedral

\footnotetext{
${ }^{5}$ Em seu notável estudo sobre a transformação das pessoas em mercadoria na vida contemporânea, ou seja, de uma sociedade de consumidores e de produtores de consumo, Zygmunt Bauman aponta o papel crucial desempenhado pela internet nessa teia de relações humanas. Bastante crítico, ele ressalta que "alguns observadores da cena contemporânea, em particular Manuel Castells e Scott Lash, saúdam a nova tecnologia virtual de atar e desatar vínculos como formas alternativas promissoras e, em alguns casos, superiores de sociabilidade, como uma cura possivelmente eficaz ou um remédio preventivo para a ameaça da solidão ao estilo consumidor; e como um estímulo à liberdade também nesse estímulo (ou seja, a liberdade de fazer e desfazer as próprias escolhas) uma forma alternativa de sociabilidade que avança um pouco no sentido de conciliar as demandas conflitantes de liberdade e segurança. Castells escreve sobre 'o individualismo em rede', Lash, sobre os 'vínculos comunicacionais'. Ambos, contudo, parecem estar tomando a parte pelo todo [...]." Porém, para Bauman, "se observado do ponto de vista da parte perdida, a 'rede' parece, de maneira perturbadora, uma duna de areia soprada pelo vento e não um canteiro de obras onde se poderão estabelecer vínculos sociais confiáveis. [...] Num mundo assim, é o ato de se livrar do indesejado, muito mais do que o de agarrar o que se deseja, que é o significado da liberdade individual. $O$ dispositivo de segurança que permite a desconexão instantânea se ajusta perfeitamente aos preceitos essenciais da cultura consumista; mas os vínculos sociais, assim como as habilidades necessárias e para estabelecê-los e mantê-los, são suas primeiras e maiores baixas colaterais." (BAUMAN, 2008, p. 137-138).
} 
Metropolitana, o Museu da República, a Biblioteca Nacional e, ao fundo, o suntuoso edifício do Congresso Nacional, pode nos ajudar a entender mais a cidade do que assistirmos do sofá da sala imagens que o noticiário nos traz das tragédias cotidianas e dos dissabores da política local e nacional. A paisagem urbana é algo a ser visto e lembrado, o cotidiano dos lugares, o pulsar das ruas e dos carros e ônibus que cruzam a cidade, a ordem e a desordem, enfim, uma coisa a ser percebida, a ser explorada, a ser visitada, a ser olhada e sentida como concerto para o corpo e a alma.

Por isso, contemplar lugares do cotidiano, o patrimônio urbano, para além de sua objetividade, é um convite a pensar a cidade sob outra interpretação que não a dos seus criadores, mas uma obra coletiva, permeada de representações simbólicas, pois,

\footnotetext{
na maioria das vezes, nossa percepção da cidade não é abrangente, mas antes parcial, fragmentária, misturada com concepções de outra natureza. Quase todos os sentidos estão em operação, e a imagem é uma combinação de todos eles (LYNCH, 2010, p.2).
}

Cada pessoa tem a sua própria afinidade com lugares de sua cidade e a imagem deles é impregnada de lembranças e significados. Além desses lugares de memória, as pessoas podem ainda ter clareza de que há espaços na cidade que podem significar muito em termos de prazer cotidiano, mas não com a apropriação negligente, a exemplo do que fazem alguns agentes do turismo, que descuidam a comunidade e os lugares.

\section{Para além da dimensão material dos espaços}

Contudo, torna-se relevante nessa abordagem o valor que os equipamentos voltados ao lazer e as atividades socioculturais que percorrem a cidade têm para mediar os desejos de fruição e de práticas das pessoas, isso porque a atividade turística deve ser vista para além da dimensão material do espaço. Na época moderna, com a alegada "falta de tempo", sabe-se que o consumo turístico, muitas vezes alienado e alienante, se mostra incapaz de compreender a beleza que existe na essência de lugares públicos ou até mesmo na cultura local, que compõe a história do lugar. A partir dessa conscientização, há que se transcender, de fato, essa materialidade, indissociável de uma rica imaterialidade, para desfrutar a viagem 
verdadeira - ou seja, desfrutar os espaços e seus objetos vistos em função dos significados que lhes atribuímos, por intermédio de nossa subjetividade.

A partir dessa análise, podemos dizer que o turismo aparece como elemento particularizador quando aplicado para uma reflexão sobre as inter-relações entre cultura e turismo, pois "se a cultura incorpora a noção de aglutinadora da vida em sociedade, ela explica porque, sob este prisma, pode ser considerada como um dos principais insumos ao fazer turístico" (GASTAL, 2008, p.114).

Daí a necessidade de procurar entender a cultura e sua importância social e política, indissociáveis da transmissão de conhecimento e de experiências de pensamento nas relações sociais, considerando que a cidade é lugar de apropriação, onde agem forças sociais diferenciadas no constructo das significações e dos bens simbólicos, revelando patrimônios que consistiram apenas das possibilidades de transformação da realidade. Como bem destaca José Luiz dos Santos (2003, p.9), "a discussão sobre cultura pode nos ajudar a pensar sobre nossa própria realidade social. De fato, ela é uma maneira estratégica de pensar sobre nossa sociedade, e isso se realiza de modos diferentes e às vezes contraditórios".

Inserido no contexto social, o homem é capaz de criar representações simbólico-sociais que se voltam para a interação social. Nesse universo, alguns indivíduos produzem símbolos; outros são receptores, assimilam e se aproximam daquilo que os identificam. Contudo, sabe-se que, na sociedade capitalista, a maior parte do tempo livre das pessoas é dedicada ao entretenimento, não como elemento ativo, mas passivo diante do que Ihes oferecem os modernos meios de comunicação de massa.

Para essa discussão, não poderemos nos furtar de trazer ao debate as relações de poder dentro de uma sociedade ou entre sociedades. Isso porque,

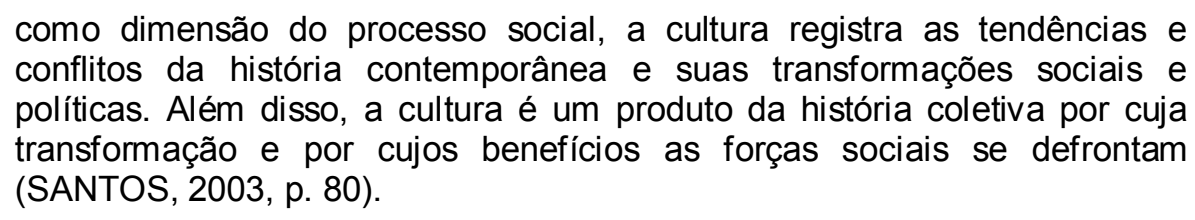

\section{A cultura como direito dos cidadãos}


Mais do que um exercício de reflexão, essas questões podem conduzir a um rico debate teórico, no qual é possível considerar a cultura não como supérflua, ou reduzida aos padrões do mercado, ou apenas como entretenimento, mas qualificada como direito de todos os cidadãos, "porque, no exercício do direito à cultura, os cidadãos, como sujeitos sociais e políticos, se diferenciam, entram em conflito, comunicam e trocam suas experiências, recusam formas de cultura, criam outras e movem todo o processo cultural" (CHAUÍ, 2006, p. 138).

Portanto, problematizar a cultura como fator essencial da prática e da reflexão sobre o turismo faz-nos entender que "ao usufruirmos formas singulares de celebração e conhecimento, nós retomamos parte de nossas identidades comuns" (PELLEGRINI; FUNARI, 2008, p. 8).

Esse pode ser um aspecto importante para o turismo moderno se for levado em conta o debate que se coloca entre a cidade como espetáculo (que, associado a setores de marketing e de captação de recursos para a realização de megaeventos, pode atrair turismo de massa) e a cidade que dá o sentido social a seus bens materiais e simbólicos. Segundo Moesch (2002, p.134), trabalhar o turismo é uma tarefa complexa pelo fato de ser um campo de "práticas histórico-sociais, que pressupõem o deslocamento do(s) sujeito(s), em tempos e espaços produzidos de forma objetiva, possibilitador de afastamentos simbólicos do cotidiano, coberto de subjetividades, em busca do prazer".

Por isso, também, a importância de conhecer e refletir a história das cidades nos seus contextos e como resultado da ação de seus moradores, repleta de lembranças a serem contadas e recontadas na tessitura do tempo, numa referência à sua materialidade como "fenômeno que se revela pela percepção de emoções e sentimentos dados pelo viver urbano e também pela expressão de utopias, de esperanças, de desejos e medos, individuais e coletivos, que esse habitar, em proximidade, propicia" (PESAVENTO, 2007, p. 14). Ao estabelecermos relações acerca das formas variadas sob as quais se consubstanciam a apropriação do espaço e onde a memória se refugia, impõe-se concordar com Hannah Arendt (2005), para quem o homem só alcança o mais alto nível de desenvolvimento na ação. Ela apontou para o debate de importantes questões que nos desafiam nos dias de hoje, tais como o sentido da política e o papel da ação no espaço público para o entendimento do mundo contemporâneo, com ênfase na exigência do pensar e do agir, questões para ela fundamentais para a resistência às tiranias. 
Para Arendt, a ação está na esfera pública e é "a única atividade executada diretamente entre os homens, sem o intermédio das coisas ou da matéria, corresponde à condição humana da pluralidade, ao fato de que homens, e não o homem, vivem na Terra e habitam o mundo" (2005, p. 15). Ao agir, o homem transforma sua essência. Os homens somente são livres enquanto agem, "pois ser livre e agir são uma mesma coisa" (ibidem, p. 199). Portanto, toda prática social e cultural é simbolicamente marcada, principalmente se ela é resultado da ação e da liberdade criativa de sujeitos que, independentes da indústria cultural, promovem a cultura, associando-a a ações sociais e comunitárias não com o propósito de produzir cultura apenas como entretenimento para atrair turismo, mas para promover acesso do cidadão aos bens e serviços da cultura. Para isso, a cidade é palco, lócus privilegiado para a formação cidadã e para o exercício da cidadania e onde vemos a transformação do espaço como elemento importante para as relações sociais. É nessa abordagem, dentro do vasto universo de uma cidade, que é possível ver, material e simbolicamente, as possibilidades efetivas da vida cotidiana.

Nessas condições, tendo o espaço como instrumento de realizações do homem, seria o caso de se indagar sobre o significado da cidadania, sem perder de vista os direitos que o termo abrange, incluído aí a cultura. Mas a cidadania "se aprende" como disse Milton Santos: "É assim que ela se torna um estado de espírito, enraizado na cultura" (2007, p.20).

Temos aqui também a aguda percepção da filósofa e professora Marilena Chauí sobre a questão do que vem a ser cidadania cultural. Em essência, seu argumento é o seguinte: a cultura não se reduz ao supérfluo, ao entretenimento, aos padrões de mercado. Para ela, a cultura se realiza como direito de todos os cidadãos:

\begin{abstract}
direito a partir do qual a divisão social das classes ou a luta de classes possa manifestar-se e ser trabalhada porque, no exercício do direito à cultura, os cidadãos, como sujeitos sociais e políticos, se diferenciam, entram em conflito, comunicam e trocam suas experiências, recusam formas de cultura, criam outras e movem todo o processo cultural.

Afirmar a cultura como um direito é opor-se à política neoliberal, que abandona a garantia dos direitos, transformando-os em serviços vendidos e comprados no mercado e, portanto, em privilégios de classe (2006, p. 138).
\end{abstract}

Consequentemente, entram em cena os atores, os sujeitos sociais e políticos, para a consagração da cidadania. Afinal, cidadania é "uma lei da sociedade que, 
sem distinção, atinge a todos e investe cada qual com a força de se ver respeitado contra a força, em qualquer circunstância" (SANTOS, 2007, p.19).

Assim é que, nos parece, cidadania e cotidiano são, igualmente, a base para a reprodução da vida na cidade. Ambos os termos trazem em si a ideia de movimento, de mudanças que se operam na cidade por intermédio dos múltiplos sujeitos fazendo o acontecer histórico. Por isso, mais do que exercício de reflexão, a cidade, representada em suas diversas manifestações, sejam estéticas ou políticoculturais, é o "lugar onde agem forças múltiplas: produtivas, territoriais, de formação e pressões sociais" (MENESES, 1984-1985, p. 199). Então, acreditamos, ela pode adquirir como patrimônio, além das obras de valor arquitetônico, outros elementos que revelam a vida, a convivência, as tensões e a ação criativa de seus moradores. Afinal, ao reconhecerem e se identificarem com o mundo em que vivem, os sujeitos partilham sua realidade e dão um sentido a ela.

\section{Turismo, entre a memória e a identidade}

Esse componente de identificação é que nos leva a concordar com Suzana Gastal (2002), quando ela afirma que, no atual momento turístico, a atividade impõe a sua força social e econômica, a cultura deve ser deslocada para suas implicações sociais em termos de identidade e memória. Para tanto, Gastal sugere lançar um olhar sobre o turismo cultural para além de sua apresentação com mero diferencial mercadológico, e um dos itens mais apropriados pelo turismo cultural, segundo ela, é o patrimônio histórico, no qual estão inseridos os bens culturais.

Ainda em sua argumentação, um bem cultural é, em geral, parte significativa da memória local, e ao focar em casos incomuns utiliza-se a categoria "lugar de memória", que incorpora em sua reflexão "uma concepção que remete diretamente à afetividade, integridade e identidades locais" (GASTAL, 2002, p.71). Sabe-se que a relação da memória com a história é um dos grandes debates da atualidade, pois a memória não é mais vista simplesmente para lembrar fatos passados. De importância fundamental para o debate teórico das ciências humanas, ela está intimamente associada a mudanças culturais e, assim como a história, também não é mais entendida para somente estabelecer os fatos como eles realmente aconteceram. Essa relação pode ser compreendida a partir da construção de uma interpretação histórica, na qual também estão indissociavelmente ligadas a 
identidade e a cultura. Gastal argumenta que a memória de uma localidade pode estar presente na produção cultural de seus moradores. Diz ela (2002, p. 76-77):

É a memória do lugar que fica registrada na música, nos versos dos poetas[...]. As diferentes memórias estão presentes no tecido urbano, transformando espaços em lugares únicos e com forte apelo afetivo para quem neles vive ou para quem os visitam. Lugares que não apenas têm memória, mas que para grupos significativos da sociedade, transformamse em verdadeiros lugares de memória.

Tal constatação impõe a construção de uma relação entre memória social e temporalidades, que remete para a questão de lembrar-se e ser lembrado, de que nos fala Arendt:

Se os mortais conseguissem dotar suas obras, feitos e palavras de alguma permanência, e impedir sua perecibilidade, então essas coisas ao menos em certa medida entrariam no mundo da eternidade e aí estariam em casa e os próprios mortais encontrariam seu lugar no cosmo, onde todas as coisas são imortais, exceto os homens (2002, p.72).

Também nos conduz a Pierre Nora, para quem "a memória é a vida, sempre carregada por grupos vivos e, nesse sentido, ela está em permanente evolução, aberta à dialética da lembrança e do esquecimento..." (1993, p. 9). Também no diagnóstico de Maurice Halbwachs, conforme citação de Alexandre (2011, p.23) "não é o indivíduo em si ou alguma entidade social que recorda, mas ninguém pode se lembrar realmente a não ser em sociedade, pela presença ou pela evocação, portanto, recorrendo aos outros ou a suas obras".

Portanto, pensar nossa herança cultural como lugar de memória, identificanos como testemunhas do nosso próprio tempo, nos traz o sentimento de pertencer e partilhar uma mesma cultura e uma identidade coletiva. Podemos, então, referenciar-nos nessa herança cultural enquanto suporte da memória social coletiva, entendendo que, diferentemente da memória individual, a memória coletiva resulta de interações sociais e processos comunicacionais. Ela tem a importante função de contribuir para o sentimento de pertencimento dos grupos sociais à cidade. A sua construção implica referências a partir "da compreensão de que a cidade é também sociabilidade: ela comporta atores, relações sociais, personagens, grupos, classes, práticas de interação e de oposição, ritos e festas, comportamentos e hábitos" (PESAVENTO, 2007, p. 14). 
Essa abordagem, que parte da intencionalidade de pensar a cidade como patrimônio, que, por sua vez, nos remete ao território, ao lugar, à paisagem, ao espaço, às datas, aos personagens históricos, às tradições e aos costumes, permite tomar como pressuposto o "sentimento de pertencer àquilo que nos pertence", como disse Milton Santos (1999, p.8), ao se referir ao território usado como sendo "o chão mais a identidade" e o "fundamento do trabalho, o lugar da residência, das trocas materiais e espirituais e do exercício da vida".

Isso é o que nos possibilita procurar entender que referências como essas possam permitir à cidade ser vista como lócus de vivência, da experiência do indivíduo com seu entorno, além, é claro, de possibilitar o chamado turismo cultural. Afinal, a cultura "indica que o domínio público, que é politicamente assegurado por homens de ação, oferece seu espaço de aparição àquelas coisas cuja essência é aparecer e ser belas" (ARENDT, 2002, p. 272). Porém, não se trata de incentivar o consumo da cultura como apenas entretenimento, mas simplesmente vê-la em sua condição de instrumento do desenvolvimento humano e que busca modificar o mundo, pois "não haveria cultura nem história sem inovação, sem criatividade, sem curiosidade, sem liberdade sendo exercida ou sem liberdade pela qual, sendo negada, se luta", conforme ensina o mestre Paulo Freire (2000, p. 30).

\section{Considerações finais: um novo olhar se impõe}

Por fim, a cidade, a cultura, a memória e o turismo não podem ser vistos, muito menos entendidos, independentemente, quando se tenta dimensionar o uso dos lugares para a atividade turística. Ainda que os termos carreguem um substrato político individual, eles devem ser vistos, para a apropriação do tempo livre, na dinâmica das relações que existem entre os lugares e suas necessidades materiais, imateriais, econômicas, sociais, e culturais.

É nessa relação, entre as partes e o todo, que se revela a importante premissa de que a capacidade inventiva do homem para intervir no mundo, com o devido exercício crítico de procurar entender o sentido real do agir e a maneira pela qual nos inserimos nele, é o que nos faz seres culturalmente construídos e, portanto, capazes de reconhecer que a paisagem apropriada e ressignificada pelo turismo está implicada nas tramas da ordem global capitalista. O importante, porém, é a capacidade de ver a história como possibilidade, e perceber a subjetividade em 
sua relação dialética com a objetividade para, então, apreender que os lugares turísticos podem estar condenados a ser palco do mercado espetacularizado ou podem ser promissores para a prática de uma cultura de turismo mais democrática e menos impactante. Podemos dizer que em ambas as possibilidades é preciso encarar o fenômeno turístico em sua simbiose com os lugares do cotidiano e na produção de bens simbólicos. É a maneira que temos, para escapar à crença de que nessa era globalizada o mundo se impõe como uma fábrica de perversidades, de discutir a questão fundamental das oportunidades oferecidas pelos lugares às atividades turísticas. Resumidamente, é como ensina Milton Santos (2004b, p. 338): "É o lugar que oferece ao movimento do mundo a possibilidade de sua realização mais eficaz".

A intenção posta aqui foi tão somente trazer à discussão, sob um esforço de reflexão teórica e conceitual, uma nova perspectiva sobre como compreender que o ser humano em sua relação com a natureza constrói, destrói, reconstrói e transforma a realidade; trata-se da compreensão do homem como ser social pensante, ético, político e cultural. 


\section{REFERÊNCIAS}

Alexandre, J. Michel. In: HALBWACHS, Maurice. A memória coletiva. São Paulo: Centauro. $2^{\text {a }}$. ed., $5^{\text {a }}$. reimpressão, 2011.

ARENDT, Hannah. Entre o passado e o futuro. Tradução Mauro W. Barbosa de Almeida. São Paulo: Perspectiva. 5a. Ed., 2a ${ }^{a}$. reimpressão, 2002.

ARENDT, Hannah. A condição humana. Tradução Roberto Raposo. Rio de Janeiro: Forense Universitária, 10ª . ed., 5 ${ }^{\mathrm{a}}$. reimpressão, 2005.

BAUMAN, Zygmunt. Vida para consumo: a transformação das pessoas em mercadoria. Rio de Janeiro: Zahar, 2008.

CHAUÍ, Marilena. Cidadania cultura: $O$ direito à cultura. São Paulo: Fundação Perseu Abramo, 2006.

COSTA, Everaldo Batista da. A concretude do fenômeno turismo e as cidadespatrimônio-mercadoria: uma abordagem geográfica. Rio de Janeiro: Livre Expressão, 2010.

FREIRE, Paulo. Pedagogia da indignação: cartas pedagógicas e outros escritos. São Paulo: Editora Unesp, 2000.

GASTAL, Suzana. Lugar de memória: por uma nova aproximação teórica ao patrimônio local. In: GASTAL, S. (org.). Turismo: Investigação e crítica. São Paulo: Contexto, 2002.

GASTAL, Susana; MOESCH, Marutschka. Turismo, políticas públicas e cidadania. Coleção ABC do Turismo. São Paulo: Aleph, 2007.

GASTAL, Suzana. Turismo e cultura: por uma relação sem diletantismos. In: GASTAL, Suzana (org.). Turismo: 9 propostas para um saber-fazer. Coleção Comunicação. Porto Alegre: EdiPUCRS, 2008.

HALL, Stuart. A identidade cultural na pós-modernidade. Tradução Tomas Tadeus da Silva e Guacira Lopes Louro. Rio de Janeiro: DP\&A, 2006. 
HARVEY, David. A produção capitalista do espaço.Tradução Carlos Szlak. São Paulo: Annablume, $2^{\text {a }}$. ed., 2006.

LYNCH, Kevin. A imagem da cidade. Coleção Mundo da Arte. São Paulo: WMF, Martins Fontes, $2^{\mathrm{a}}$. ed., 2010.

MCGREW, Anthony. A global society?. In: HALL, Stuart; HELD, David; MCGREW, Antony. Modernity and its futures. Cambridge: Polity Press / Open University Press, 1992.

MARX, Karl; ENGELS, Friedrich. A sagrada família. São Paulo: Boitempo, 2003.

MENESES, Ulpiano Bezerra de. O museu na cidade $X$ a cidade no museu: para uma abordagem histórica dos museus de cidade. Revista Brasileira de História. São Paulo: v.5, n. 8/9, p. 199, set. 1984/abr. 1985. Dsiponível em:

http://www.anpuh.org/revistabrasileira/view?ID REVISTA BRASILEIRA=32. Acesso em: 13 set. 2011.

MOESCH, Marutschka. A produção do saber turístico. São Paulo: Contexto, 2002.

MOESCH, Marutschka. O fazer-saber turístico: possibilidades de superação e limites. In: GASTAL, Suzana. Turismo: 9 propostas para um saber-fazer. Porto Alegre: EdiPUCRS, 4․ ed. revisada, 2008.

NORA, Pierre. Entre memória e história: A problemática dos lugares. Revista do Programa de Estudos Pós-Graduados em História e do Departamento de História. PUC/SP, no 10, p. 7-28, dez.1993. Dsiponível em: www.pucsp.br/projetohistoria/downloads/revista/PHistoria10.pdf. Acesso em 13/09/2011.

PELLEGRINI, Sandra C. A.; FUNARI, Pedro Paulo. O que é patrimônio cultural imaterial. São Paulo: Brasiliense, 2008.

PESAVENTO, Sandra Jatahy. Cidades visíveis, cidades sensíveis, cidades imaginárias. Revista Brasileira de História. São Paulo: v. 27, n. 53, p.14, jun. 2007. Disponível em: http://www.scielo.br/pdf/rbh/v27n53/a02v5327.pdf. acesso em 13/09/2011. 
ROSSI, Paolo. O passado, a memória, o esquecimento: seis ensaios da história das idéias. São Paulo: Editora Unesp, 2007.

SANTOS, José Luiz dos. 0 que é cultura. Coleção Primeiros Passos. São Paulo: Brasiliense, 16ª . ed., 9 ${ }^{\mathrm{a}}$. reimpressão, 2003.

SANTOS, Milton. O dinheiro e o território. Revista GEOgrafia, Rio de Janeiro, ano 1, n. 1, p. 7-13, jun.1999. Disponível em:

http://www.uff.br/geographia/ojs/index.php/geographia/article/view/2/2. Acesso em: 13 set. 2011.

SANTOS, Milton. Testamento intelectual. São Paulo: Editora Unesp, 2004a.

SANTOS, Milton. A natureza do espaço. São Paulo: Edusp, 4a ${ }^{\text {a }}$ ed., 2004b.

SANTOS, Milton. Pensando o espaço do homem. São Paulo: Edusp, 5ª. ed., 2009.

SANTOS, Milton. O espaço do cidadão. São Paulo: Edusp, 7ª . ed., 2007.

SANTOS, Milton. Por uma outra globalização: Do pensamento único à consciência universal. Rio de Janeiro: Record, 20ª . ed., 2011.

Artigo:

Recebido em: 25/05/2012

Aceito em: 23/12/2012 